\title{
Injury and injury rates in Muay Thai kick boxing
}

\author{
S Gartland, M H A Malik, M E Lovell
}

\begin{abstract}
Objective-To determine the type and number of injuries that occur during the training and practice of Muay Thai kick boxing and to compare the data obtained with those from previous studies of karate and taekwondo.
\end{abstract}

Methods-One to one interviews using a standard questionnaire on injuries incurred during training and practice of Muay Thai kick boxing were conducted at various gyms and competitions in the United Kingdom and a Muay Thai gala in Holland.

Results-A total of 152 people were questioned, 132 men and 20 women. There were 19 beginners, 82 amateurs, and 51 professionals. Injuries to the lower extremities were the most common in all groups. Head injuries were the second most common in professionals and amateurs. Trunk injuries were the next most common in beginners. The difference in injury distribution among the three groups was significant $(p \leqslant 0.01)$. Soft tissue trauma was the most common type of injury in the three groups. Fractures were the second most common in professionals, and in amateurs and beginners it was sprains and strains $(p \leqslant 0.05)$. Annual injury rates were: beginners, $13.5 / 1000$ participants; amateurs, $2.43 / 1000$ participants; professionals, $2.79 / 1000$ participants. For beginners, $7 \%$ of injuries resulted in seven or more days off training; for amateurs and professionals, these values were $4 \%$ and $5.8 \%$ respectively.

Conclusions-The results are similar to those found for karate and taekwondo with regard to injury distribution, type, and rate. The percentage of injuries resulting in time off training is less.

(Br F Sports Med 2001;35:308-313)

Keywords: injury rates; Muay Thai kick boxing

Muay Thai is the martial art of Thailand. It allows the use of punches, kicks, knees, and elbows. It promotes both physical and mental development, with many instructors placing great emphasis on discipline, respect, and spirituality. ${ }^{1}$ It is rapidly increasing in popularity and has an estimated one million participants world wide (International Muay Thai Kickboxing Federation (IAMTF) International Office). Despite this, little is known about the type of injuries that occur. This is in great contrast with other martial arts such as taekwondo and karate, about which much more work has been published.

The nature of the activity involved will depend on the level of the individual. Classes usually begin with a 15-30 minute session of warm up, stretching, and callisthenics. This is generally followed by kick, punch, knee, and elbow drills and then various amounts of pad, bag, and sparring work. Sparring contact varies with the level. Beginners are allowed no contact. Amateurs are allowed full contact and wear shinguards, groin protector, trunk pads, boxing gloves, elbow pads, mouthguards, and protective headgear. Professionals use full contact and wear mouthguards, groin protectors, and boxing gloves. All body targets are permissible except for the groin.

A literature search for Muay Thai and kick boxing found only a case report and a single study monitoring renal and liver functions and muscle injuries. The case report was that of a 23 year old kick boxer with spontaneous rupture of the extensor pollicis longus tendon, which occurred while he was doing reverse press ups on the dorsum of his hands with his wrists hyperflexed. ${ }^{2}$ Sangsirisuwan et $a \beta^{3}$ investigated renal and liver function and muscle injuries during training and after competition. They found no effect on liver or renal function but damage to skeletal muscle may occur in both settings.

A review of published data for all martial arts found a number of trends. Soft tissue trauma, haematomas, and lacerations have consistently been shown to be the most common injuries. Younger participants and those with less experience have a higher risk of injury. ${ }^{4-10}$ Sparring, tournaments, and competitions are associated with fewer injuries, but those that do occur are more severe. The head, face, and neck have been shown to be the site of about $50 \%$ of all injuries. The most common type of injuries are lacerations, contusions, epistaxis, and haematomas. ${ }^{6-9}$ The lower extremity is the next most commonly injured site. Again, lacerations, contusions and haematoma formation are the most common injuries. ${ }^{10}$ Fractures of the digits are relatively common too. This is not surprising as the feet and legs are often given little or no protection, and the forces created are large. ${ }^{11}$ Different martial arts are associated with particular injury patterns. Taekwondo and karate are associated with trauma to the lower extremities and head, ${ }^{5712}$ kendo with left side injuries, ${ }^{13}$ and judo with complete acromioclavicular separation. ${ }^{14}$

Numbers of fractures have been recorded in several papers. ${ }^{12-19}$ In the study of Critchley et $a l^{20}$ of three British Shotokan karate championships, fractures were recorded as being $6 \%$ of all injuries. Burks and Satterfield, ${ }^{21}$ who only looked at foot and ankle injuries, reported similar rates, although digital fractures were reported to be as much as $10 \%$ of all injuries. This is similar to that recorded by Oler et $a l^{9}$ at two national taekwondo competitions, in which fractures were $7 \%$ of all injuries recorded. 
A definition of a reportable injury is often one that results in the athlete missing more than one day of training. Injuries that caused this in taekwondo athletes ran at $15 \%$ of all injuries, in both sexes. This was based on injuries/min of competition. In men this was $23.58 / 1000 \mathrm{~min}$, and $13.51 / 1000 \mathrm{~min}$ for women. For men this is less than for wrestling $(31.75 / 1000 \mathrm{~min})$ and American football $(30.97 / 1000 \mathrm{~min})$. In women this is less than for gymnastics $(18.09 / 1000 \mathrm{~min})$ and soccer $(15.31 / 1000 \mathrm{~min}) .^{22}$

A survey of athletes during and after a tournament and training sessions found that about $60 \%$ of injuries go unreported. A number of reasons were suggested: recall of minor injuries can be poor, denial of vulnerability, raised pain threshold, fear of instructors' perception of injury, and confusion as to what is an injury. ${ }^{23}$

\section{Methods}

A questionnaire was devised with advice from a senior instructor at the Muay Thai Centre of
Excellence in Manchester (fig 1). A one on one method of interview was used to ensure that the questionnaires were all fully completed. Interviews were conducted at various gyms and competitions in the United Kingdom and at a Muay Thai gala in the Netherlands. The nature and purpose of the interview was explained. Questions were asked on age, sex, amount of practice time, level of contact, and level of proficiency (beginners, amateurs, or professionals). The last of these was used instead of rank, as various participants had trained in different forms of kick boxing but had only recently converted to Muay Thai, not all gyms used the same ranking systems, and recall of rank was often poor. Participants were asked about any injuries incurred during training and the practice of Muay Thai. Subjects chosen had trained for a minimum of one year.

Injuries accrued by participants as they advanced between training grades were differentiated throughout the timescale investigated.

\section{QUESTIONNAIRE \\ The purpose of this study is to obtain information on the type and number of injuries sustained during the training and practice of Muay Thai. All information is confidential. No names are needed. The information gathered will be collated and presented to the IAMTF and Medical community. \\ Age: Sex: Male/Female \\ Hours per week training: Hours per Month:}

Level of contact (please tick):

None

Touch sparring

Full contact

Competition

How long have you been training?

Would you describe yourself as (please tick):

Beginner

Amateur

Professional

Please list INJURIES in LAST 6 MONTHS:

Injury

Contact level (please circle)

None/Touch sparring/Full contact/Competition

None/Touch sparring/Full contact/Competition

None/Touch sparring/Full contact/Competition

None/Touch sparring/Full contact/Competition

INJURIES IN LAST 12 MONTHS:

Injury

Contact level (please circle)

None/Touch sparring/Full contact/Competition None/Touch sparring/Full contact/Competition None/Touch sparring/Full contact/Competition None/Touch sparring/Full contact/Competition

Figure 1 Questionnaire used to determine injury rates in Muay Thai kick boxing. 
Table 1 Total numbers of injuries reported in the 152 Muay Thai kick boxers examined

\begin{tabular}{lr}
\hline Head and neck contusions & 545 \\
Head neck lacerations & $\sim 158$ \\
Head neck strain & 10 \\
Epistaxis & 40 \\
Jaw fracture & 1 \\
Nasal fracture & 22 \\
Teeth avulsion & 1 \\
Shoulder subluxation & 2 \\
Shoulder strain & 11 \\
Wrist strain & 10 \\
Carpal fracture & 9 \\
Metacarpal fracture & 10 \\
Phalanx fracture & 9 \\
Thumb hyperextension & 6 \\
Trunk contusion & -8 \\
Back strain & 15 \\
Groin strain & 6 \\
Rib fracture & 13 \\
Forearm fracture & 2 \\
Ankle strain & 9 \\
Foot contusion & $\sim 98$ \\
Foot fracture & 3 \\
Lower leg fracture & 1 \\
Toe fracture & 10 \\
Toe strain & 8 \\
Leg contusion & 298 \\
Leg haematoma & 8 \\
Leg strain & 8 \\
Knee strain & 17 \\
Shin contusion & $\sim 780$ \\
Shin haematoma & 8 \\
&
\end{tabular}

Time off was strictly defined as enforced absence from training (and competing where applicable) because of injuries sustained during training/practice.

All information collected remained confidential. Information was stored on an SPSS database and a Microsoft Excel spreadsheet for analysis.

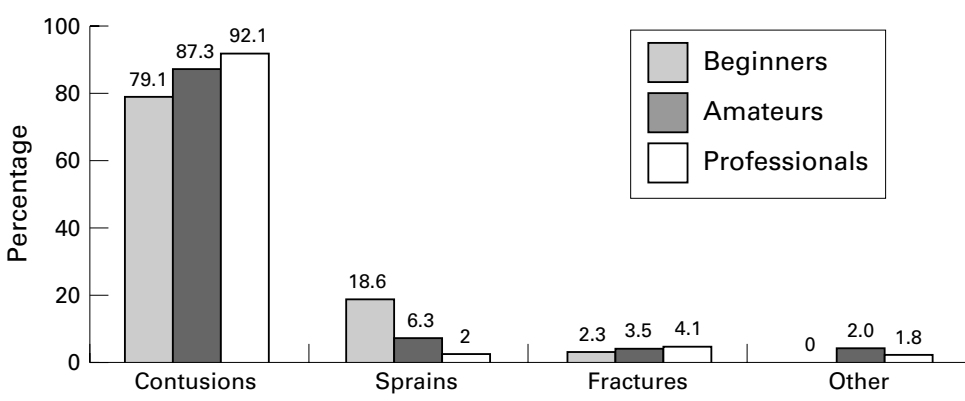

Figure 2 Percentage distribution of injuries by generic type.

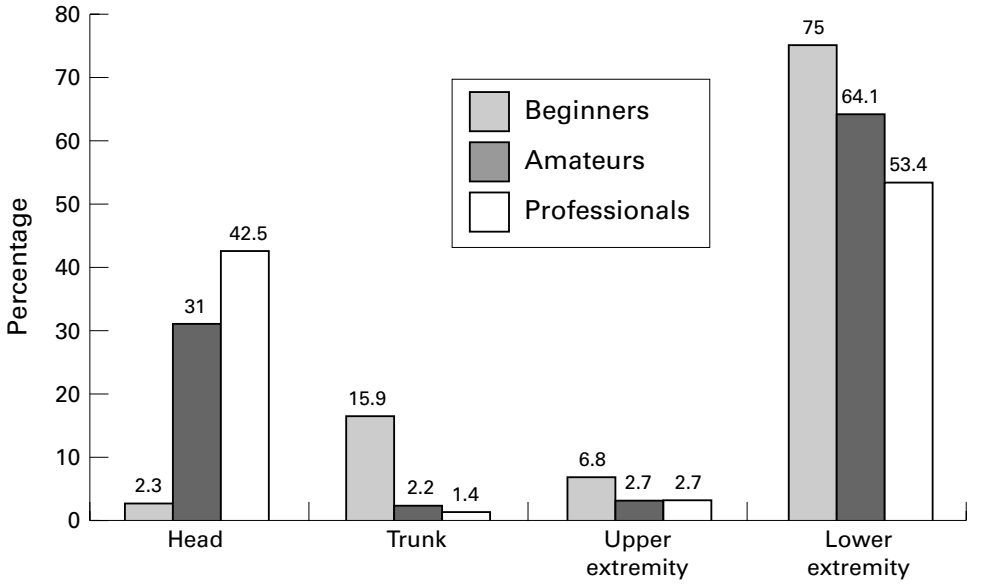

Figure 3 Anatomical distribution of injuries.

\section{Results}

There were 19 beginners, 82 amateurs, and 51 professionals (132 men and 20 women). The median age was 26 (range 14-51). Years of training ranged from one to 30 (mean of eight; median 4.5). Table 1 gives total numbers of injuries reported. A $\chi^{2}$ analysis of the groups showed that there was a significant difference $(p \leqslant 0.01)$ in the likelihood of being injured between the three groups. Beginners had the smallest total number of injuries, then amateurs, and all professionals reported an injury of some sort.

\section{INJURY TYPES}

In all groups, most injuries were soft tissue ones such as contusions and lacerations. Sprains/strains were the second most common type of injury in beginners and amateurs. For professionals, it was fractures. Figure 2 shows the percentage distribution of injuries by generic type. $\chi^{2}$ analysis of the results showed these differences to be significant $(p \leqslant 0.05)$.

Recall of minor injuries such as contusions and superficial lacerations tended to be poor in subjects who had ten or more such injuries.

ANATOMICAL DISTRIBUTION OF INJURIES

To describe the anatomical distribution of injuries, the data were collated into variables of head, trunk, upper extremity and lower extremity injuries. Figure 3 gives the totals (by percentage). In beginners the lower extremity was the most common site of injury $(75 \%)$, then the trunk $(15.9 \%)$, followed by the upper extremity $(6.8 \%)$, with head injuries being only $2.3 \%$ of all injuries. This distribution differed from that of amateurs and professionals. The legs were still the most commonly injured area (64\% amateurs and 53\% professionals), but, unlike beginners, the second most commonly injured site was the head. The trunk was the least commonly injured site in both these groups. The differences in anatomical area affected was found to be significant $(p<0.01)$.

\section{INJURY RATES}

To obtain a rough guide of injury rates, the following equation was used:

Injury rate per 1000 participants per year $=$ (No of injuries/No of years) $\times(1000 /$ No in each group)

If contusions, superficial lacerations, and haematomas are not included because of the inaccurate reporting of these, then the rates are:

Beginners $=(10 / 39) \times(1000 / 19)=13.5$ injuries/1000 participants/year

Amateurs $=(124 / 613) \times(1000 / 82)=2.43$ injuries/1000 participants/year

Professionals $=(94 / 659) \times(1000 / 51)=2.79$ injuries/1000 participants/year

If soft tissue injuries are included, because of their preponderance compared with more serious injury, the rates change to:

Beginners $=(44 / 39) \times(1000 / 19)=59.3$

injuries/1000 participants/year

Amateurs $=(326 / 613) \times(1000 / 82)=7.1$

injuries/1000 participants/year 


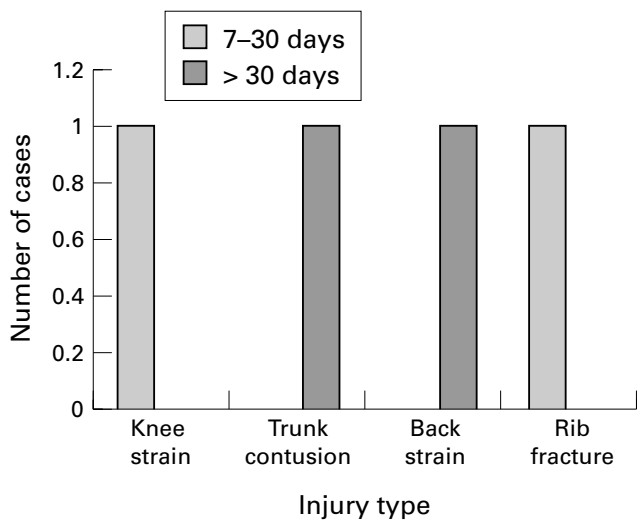

Figure 4 Injuries and number of days missed as a result in beginners.

Professionals $=(1157 / 659) \times(1000 / 51)=$ 21.3 injuries/ 1000 participants/year

The high rate for beginners is skewed by two participants who suffered an abnormally high number of soft tissue injuries.
TIME OFF TRAINING

Some $7 \%$ of injuries in beginners required time off training. In one case of knee strain and one rib fracture, 7-30 days of training were missed. In one case of back strain, more than 30 days were missed, and similarly for a series of trunk contusions (fig 4). The variety of injuries resulting in time off was much narrower than in the other two groups.

Some $4 \%$ of injuries in amateurs resulted in time off training. Injuries requiring more than 30 days off training were six cases of ankle strain/sprain, five cases of knee strain, three rib fractures, and three shoulder strains (fig 5).

Some $5.8 \%$ of injuries in professionals required time off training: eight nasal fractures, six rib fractures, and five metacarpal fractures (fig 6).

\section{Discussion}

As with previous studies on the martial arts, soft tissue injuries have been shown to be the most common type of injury, contributing to at

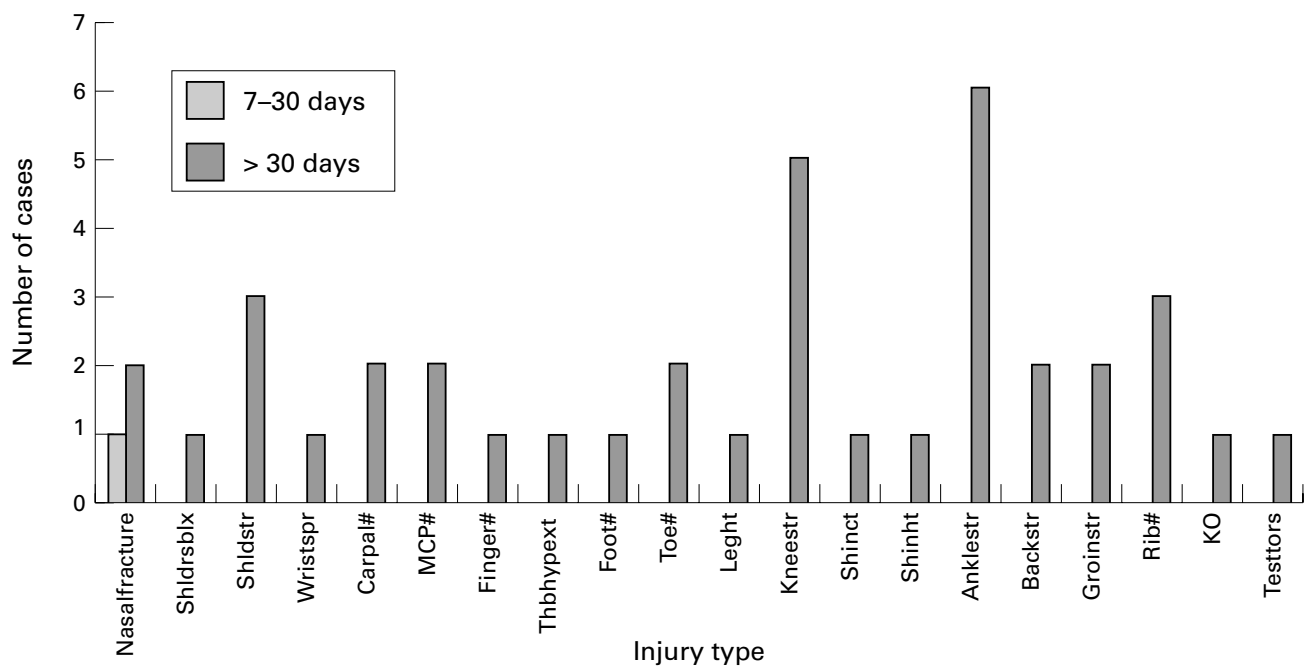

Figure 5 Injuries and number of days of training missed as a result in amateurs. \#, Fracture; ct, contusion; $h$ t, haematoma; KO, knock out; MCP, metacarpal; sblx, subluxation; Shldr, shoulder; spr, sprain; str, strain; Testtors, testicular torsion; Thbhypext, thumb hyperextension.

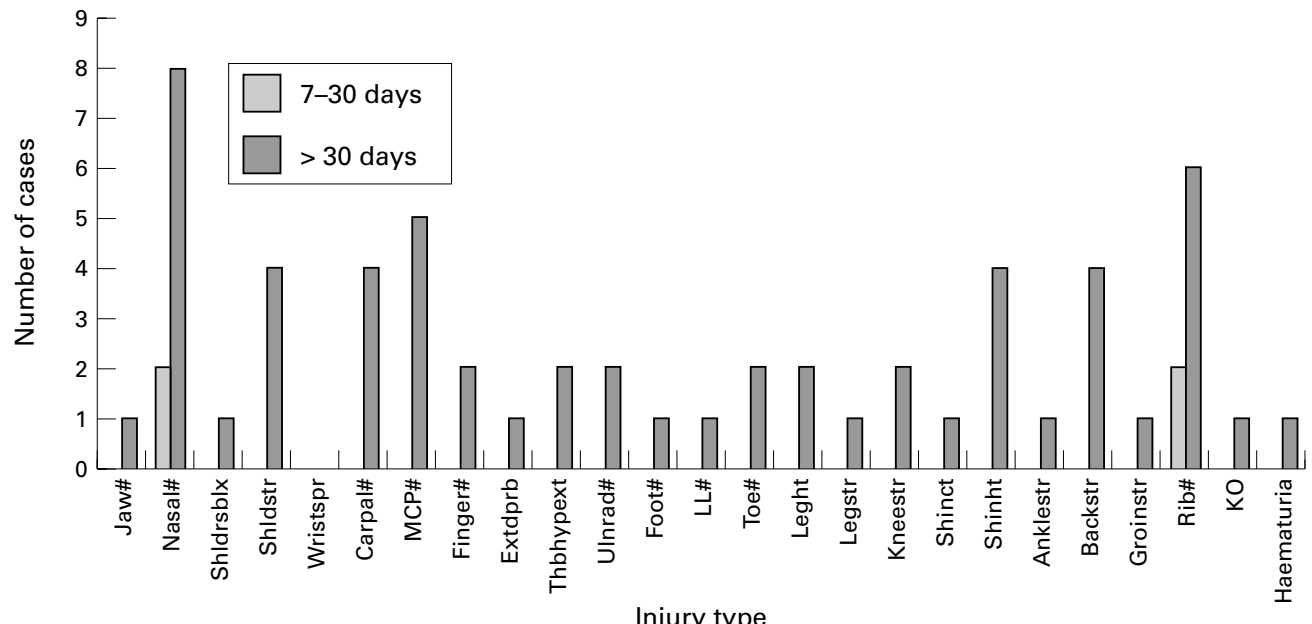

Figure 6 Injuries and number of days missed as a result in professionals. \#, fracture; ct, contusion; Extdprb, non-specific extensor tendon problem; ht, haematoma; KO, knock out; LL, lower leg; MCP, metacarpal; sblx, subluxation; Shldr, shoulder; spr, sprain; str, strain; Thbhypext, thumb hyperextension; Ulnrad, ulnar/radius. 
least $80-90 \%$ of all injuries. The actual value is probably higher because, during interviews, subjects displayed poor recall as to the number and occurrence of such injuries. In addition, if subjects reported around 10 or more contusions, this was recorded as 10 . This particularly affects fighters in whom shin contusions are an accepted injury incurred by the use of shins to block an attackers kicks and knees.

Sprains and strains were the second most common type of injury in beginners and amateurs $(p<0.01)$. This would seem to be a readily reducible statistic. Many of the subjects readily admitted to inadequate warm up before the occurrence of such injuries. Instructors should therefore pay particular attention to this part of the training session and advise their students accordingly. The bruising in beginners was recorded in particular subjects and affected the feet and shins. Generally beginners perform little if any contact activity.

Fractures are the second most commonly reported injury in professionals, the most common sites being the nose, carpal bones, metacarpals, digits, and ribs. This is perhaps not surprising as the forces involved are a lot higher, less protective equipment is used, and subjects are likely to train harder. Other injuries of note were one reported case of testicular torsion, one case of haematuria after a professional fight, and three reported knockouts. None of these injuries were reported by beginners. This probably reflects the noncontact nature of their training. There were no definite reports of dislocation, but a number of subjects reported subluxation of the shoulder associated with fighting.

The distribution of injuries was significantly different between the three groups $(p \leqslant 0.01)$. The most common site of injury was the lower extremity. This is similar to karate and taekwondo. ${ }^{78}$ The forces involved are significant, ${ }^{11}$ and the attacker is often more severely injured than the defender. ${ }^{21}$ The head is the second most common site of injury in amateurs and professionals (the least in beginners). Participants should be aware that repeated head trauma increases the risk of post traumatic encephalopathy. Those that participate at full contact level over long periods are most at risk. The latency of symptoms can be years to decades. ${ }^{24}$

The low injury rates from this study mirror those of previous studies of different martial arts. Indeed, the NEISS data showed martial arts injuries to be 1/20th of those of American football (3.5 compared with 74.6 injuries per 1000 participants). ${ }^{25}$ More significantly it showed them to be safer than golf (5.4 injuries/ 1000 participants/year) and general exercise (6.9 injuries/1000 participants/year) if soft tissue injuries are excluded. These figures are probably different for those who compete, and more specific information on injury rates in competition are needed. There is also the problem of underreporting. ${ }^{23}$ The injury rate for beginners in our study is considerably higher because of two subjects with an exceptional number of injuries. It would be preferable to study larger numbers in this group, although this finding does support previous evidence that less experienced martial artists are at a higher risk of injury. The injury rates calculated in this study are an approximation. The formula used was rigid and did not take account of missed training. Fassman (unpublished data, 1979; cited by Birrer ${ }^{6}$ ) calculated that actual practice time is $30 \%$ less than recorded training time because of periods of planned or unplanned absence.

The percentage of injuries resulting in time off training $(<10 \%)$ was less for all groups than that reported for taekwondo athletes $(15 \%$ of injuries). ${ }^{22}$ This difference is probably due to the nature of the studies. The taekwondo rates were calculated at full contact, competitive bouts. Such situations are associated with increased incidence and greater severity of injury. ${ }^{6}$ The type of injury resulting in time off for beginners was noticeably much more limited and commonplace than those sustained by amateurs and professionals. This probably reflects the limited and non-contact nature of the sparring of beginners.

As with all studies this one has a number of weaknesses. The interviews were conducted at gyms and events. Therefore those who were injured and consequently not participating will have been selected out. There was also the problem of inaccurate reporting, particularly of bruises. Many subjects were unclear as to what an injury was and saw them only as something severe or debilitating. As a retrospective study, there is also the problem of poor recall. It can be expected that recall of severe and painful injuries will be better than that of minor trauma.

Many thanks to Grand Master Woody, Master Krin, Ronnie Green and IAMTF (Manchester) for all their help and advice.

1 Suhongsa, C. Muay Thai. Manchester: IAMTF, 1999.

2 Lloyd TW, Tyler MPH, Roberts AHN. Spontaneous rupture of extensor pollicis longus tendon in a kick boxer. Br F Sports Med 1998;32:178-9.

3 Saengsirisuwan V, Phadungkij S, Pholpramool C. Renal and liver functions and muscle injuries during training and after competition in Thai boxers. Br F Sports Med 1998;32:3048 .

4 Bushbacher RM, Shay T. Martial arts. Phys Med Rehabil Clin N Am 1999;10:35-47.

5 Wilkerson LA. Martial arts injuries. $f$ Am Osteopath Assoc 1997;97:221-6.

6 Birrer RB. Trauma epidemiology in the martial arts. The results of an 18-year international survey. Am J Sports Med 1996;24(suppl 6):S72-9

7 Stricevic MV, Patel MR, Okazaki T, et al: Karate: historical perspective and injuries sustained in national and international tournament competitions. Am f Sports Med 1983; 11:320-4

8 Zemper ED, Pieter W. Injury rates during the 1988 US Olympic trials for Taekwondo. Br f Sports Med 1989;23: $161-4$

9 Oler M, Tomson W, Pepe H, et al. Morbidity and mortality in the martial arts: a warning. F Trauma 1991;31:251-3.

10 McLatchie, G.R. Analysis of karate injuries sustained in 295 contests. Injury 1976;8:132-4.

11 Schwartz ML, Hudson AR, Fernie GR, et al. Biomechanical study of full-contact karate contrasted with boxing. $\mathcal{F} \mathrm{Neu}$ study of full-contact

12 Birrer RB, Birrer CD. Martial arts injuries. Physician and Birrer RB, Birrer CD. Martial
Sportsmedicine 1982;10:103-8.

13 Dvorine W. Kendo: a safer martial art. Physician and Sports Medicine 1979;7:87-9.

4 Zarzycki W, Lorczynski A, Ziolkowski W. Nonoperative treatment of acute, grade III acromioclavicular dislocation in judo competing athletes. Chir Narzadow Ruchu Ortop Pol 1998;63:321-7.

15 Tenverget EM, Ten Duis HJ, Klasen HJ. Trends in sports injuries, 1982-1988: an in-depth study on four types of sport. F Sports Med Phys Fitness 1992;32:214-20.

6 Siana JE, Borum P, Kryger H. Injuries in taekwondo. $\mathrm{Br} F$ Sports Med 1986;20:165-6.

7 McLatchie GR. Karate and karate injuries. Br F Sports Med 1981;15:84-6.

18 Plancher KD, Minnich JM. Sports specific injuries. Clin Sports Med 1996;15;207-19.

19 McLatchie GR, Davies JE, Caulley JH. Injuries in karate: a case for medical control. $\mathcal{F}$ Trauma 1980;20:956-8. 
20 Critchley GR, Mannion S, Meredith C. Injury rates in Shotokan karate. Br F Sports Med 1999;33:174-7.

21 Burks JB, Satterfield $\mathrm{K}$. Foot and ankle injuries among martial artists. Results of a survey. 7 Am Podiatr Med Assoc 1998;88:268-78.

22 Zemper ED, Pieter W. Injury rates in junior and senior national taekwondo competition. Proceedings of the first IOC World Congress of Sports Science. Amsterdam: IOC, 1989: $219-20$.
23 Birrer RB, Birrer CD. Unreported injuries in the martial arts. Br F Sports Med 1983;17:131-4.

24 Rimel RW, Giordani B, Barth JT, et al. Disability caused by minor head injury. Neurosurgery 1981;9:221-8

25 United States Consumer Products Safety Commission. NEISS data highlights. Washington DC: United States Consumer Products Safety Commission, 1979-1994:vols $2-18$.

Take home message

Injury rates and types in Muay Thai kick boxing mirror those reported in karate and taekwondo and probably represent an underreporting of injuries. More strategies for injury reduction need to be defined.

\section{British Association of Sport and Exercise Medicine in association with the National Sports Medicine Institute}

\section{Education programme 2001}

\section{BASEM Congress}

Vale of Glamorgan, Wales. Further details:

Tel/Fax: +44 (0)1928 732961; email: basemoffice@compuserve.com

Injury Management and Medicine: lower limb

Lilleshall Hall National Sports Centre

\section{Current Concepts}

Topic, date, and location to be confirmed
25-28 October

18-23 November

\section{December}

For further details of these courses please contact Mr Barry Hill, The National Sports Medicine Institute, c/o Medical College of St Bartholomew's Hospital, Charterhouse Square, London EC1M 6BQ.

Tel: 02072510583 (ext 237); Fax: 0207251 0774; email: barry.hill@nsmi.org.uk Web site: www.nsmi.org.uk 